SHADECK et. al., Atuação da Secretaria Nacional de Defesa Civil (SEDEC) na Gestão de Riscos e Resposta a Desastres Naturais. In: CONSAD DE GESTÃO PÚBLICA, 6. Brasília, 2013. Anais..., Brasília: CONSAD. Disponível em: <http://consadnacional.org.br/wpcontent/uploads/2013/05/072-A-ATUA\%C3\% 87\%C3\%830-DA-SECRETARIA-NACIONAL-DEDEFESA-CIVIL-SEDEC-NA-GEST\%C3\% 830-DE-RISCOS-E-RESPOSTA-A-DESASTRESNATURAIS.pdf $>$. Acesso em: maio de 2016.

ELTON KLEITON ALBUQUERQUE DE ALMEIDA

(Centro de Previsão de Tempo e Estudos Climáticos (CPTEC), Tecnologista (meteorologista), Rodovia Dutra, Km 39, Cachoeira Paulista -SP. E-mail: eltonkleiton@gmail.com)

\title{
O PENSAMENTO REGIONAL E A ESTRUTURA DA GEOGRAFIA: APRECIAÇÃO HISTORIOGRÁFICA
}

\author{
GEOGRAFIA, Rio Claro, v. 43, n. 2, p. 350-357, mai./ago. 2018.
}

\section{INTRODUÇÃO}

A Geografia tem sido definida como um campo disciplinar abrangente, multidisciplinar e que tem ostentado, ao longo da sua ontologia, evidentes alterações temáticas, e reformulações teóricas, metodológicas e técnicas, não obstante o ramo do saber manter a sua estrutura fundamental e permanente herdada da experiência grecoromana, se é que desejamos valorizar e reconhecer as suas origens mais remotas.

Esta é a representação da Geografia hoje prevalecente, uma representação, portanto, francamente inclusiva, e, inconclusiva. Tal representação revela-se útil seja ao exercício profissional propriamente dito no âmbito da disciplina e aos historiadores mais interessados no nível conceitual/metodológico da construção da Geografia, por um lado, seja aos esforços historiográficos mais culturais ou sociologizados que buscam narrar as experiências da história da disciplina em diferentes contextos temporo-espaciais visando alimentar agendas críticas e análises políticas.

O presente artigo entende que a Geografia, no seu conjunto, exibe uma estrutura articulada conciliando duas possibilidades metodológicas - duas atitudes cognitivas -, nomeadamente, a atitude geral, por um lado, e a atitude corográfica ou regional por outro. Afirma-se aqui que não existe superioridade cognitiva, ou maior precisão científica, ou ascendência ou primazia epistemológica ou de eficácia na produção de "verdades" de um estilo metodológico sobre o outro. Eles são, simplesmente, estilos diferentes nos seus escopos e nos seus respectivos resultados.

$\mathrm{O}$ artigo evidentemente reconhece que os dois estilos cognitivos que a disciplina mostra, o geral e o corográfico, não são eles frutos ou eclosões da experiência têmporoespacial europeia do Iluminismo e da decorrente institucionalização da Geografia. Resulta disto que a crença na fundação moderna da Geografia no formato do pensamento ou da Geografia Regional no ambiente europeu merece ser problematizada. Em primeiro lugar, há de se reconhecer que a noção de fundação carece de qualquer utilidade para a prática profissional no campo da Geografia; em segundo lugar, pode-se franca e seguramente afirmar que a institucionalização da disciplina no final do século 19 é ocasião na qual se formata burocraticamente a metodologia regional - propriamente a domesticação, moderna, digamos assim, do ramo do pensamento geográfico (a corography) cujas origens, cuja fundação mesma remonta às civilizações da Antiguidade. 
Se a ninguém é permitido afirmar que a Filosofia foi fundada por modernos, o mesmo vale para a Geografia, caso não cedamos às superstições historiográficas. A noção de região, ou de cosmos harmonizado, ou o georefenciamento (coordenadas), três ideias fundamentais na metodologia regional da disciplina, elas três nos vieram da experiência cultural greco-romana e, sobrevivendo em nichos cultivados do ambiente medieval, foram difundidas no Renascimento e Era das Navegações, como o indica Caraci (2001, p.122), servindo de base ao planejamento e à realização das explorações transoceânicas da circunavegação da África e da descoberta da América.

A dualidade cognitiva mencionada remonta então ao mundo greco-romano, onde se expressava mediante dois termos: physis (geral) e corography (regional)(GOMES, 1995; LENCIONI, 2003). Enquanto o corógrafo se encarregava de reconhecer as terras e registrar, descrever as suas características, o phisikói - termo empregado por Aristóteles para denominar os estudiosos da natureza (The Basic Works of Aristotle, McKEON) -, por outro lado, indagava acerca das leis, das repetições e regularidades dos eventos e, portanto, das possibilidades de predição dos fenômenos no campo natural (GLAECKEN , 1967; PATTISON, 1964; TATHAM, 1967; BORNHEIM, 1967). O fato é que os povos bárbaros até então - germanos, francos, anglos, etc - foram assimilando progressivamente as noções e as práticas geográficas gerais e corográficas de origem clássica à proporção que se iam latinizando sob a influencia do Império Romano e seu prolongamento, a Igreja Católica.

O Artigo está dividido em 3 partes, além desta Introdução e das Considerações Finais. Na parte 1 se procede à exposição das raízes do posicionamento da Geografia Regional (corografia) na estrutura da Geografia; na parte 2 aborda-se a emergência da face moderna do pensamento regional; na parte 3 enfoca-se o formato da Geografia Regional quando da institucionalização disciplinar.

\section{O POSICIONAMENTO DA GEOGRAFIA REGIONAL NA GEOGRAFIA: ANTECEDENTES}

Antes do estabelecimento da sua formatação moderna decorrente da institucionalização, a Geografia frequentemente foi tida como astronomia. Repetidamente também a Geografia foi sinonimizada ao que hoje se chamaria de Geografia Física. Casos assim sugerem que a Geografia ante disciplinar correspondia ao que no vocabulário filosófico grego tem-se como physis (Gr.= na língua grega).

A atividade da descrição dos lugares, por sua vez, era denominada corografia (chora, Gr.) -, irrelevante estivessem sendo descritos aspectos culturais/sociais/humanos, ou aspectos naturais. Estava fixada, assim, a dualidade dos estilos de pensamento dentro da Geografia, e a cisão decorrente projetou-se sem intermitências, com a romanização das tribos bárbaras, do horizonte greco-romano até os dias atuais, forjando uma tradição com efeitos polêmicos e controversos no pensamento geográfico. Modernamente, a controvérsia se evidenciou quando a doutrina da análise espacialeconômica encontrou a reação crítica dentro da disciplina representada na recusa ao emprego dos métodos do positivismo lógico no estudo dos comportamentos espaciais humanos (BARROS, 2012 a).

Críticas em revisões de ramos sistemáticos da disciplina afirmando que certos modelos geográficos pressuporiam comportamentos humanos constantes - desvalorizando o papel dos indivíduos e das reações humanas na construção das propriedades do espaço geográfico - são ecos recentes da controvérsia em torno do uso do raciocínio do tipo physis, por um lado, ou do tipo descritivo (corográfico) por outro, dentro da Geografia (BARROS, 2009).

A ideia do cosmos ordenado, dizendo-o com redundância, noção cara ao physikói, na Geografia, reconhece-se ou se projeta na imaginação planetária humboldtiana,. Mas, por outro lado, a ideia de cosmos é também reconhecida no projeto da imaginação regional totalizante dos finais do século 19 e começos do século 20. Neste último caso, 
a região é imaginada como um pequeno mundo harmonizado e positivamente existente, e que caberia à Geografia descobri-lo e comunicar a sua existência singular ou peculiar (idios, Gr.) através duma peça ou produto escrito, a denominada monografia regional.

A dualidade clássica da Geografia, entre physis e corografia, é sempre simbolizada por duas personalidades: Strabão e Ptolomeu. Strabão ou Strabo talvez tenha nascido em $63 \mathrm{aC}$, e era também reconhecido como historiador e seguidor da tradição dos estudos de Heródoto (BARNES, 1921, p.35-6; HOLT-JENSEN, 1988, p.12: LENCIONI, 2003, p.46). Cláudio Ptolomeu, acredita-se, provavelmente viveu entre o ano 100 e o ano 178 da Era Cristã, e firmou o seu nome na história do pensamento ocidental como astrônomo e geógrafo, sendo o seu maior interesse a physis, e, apenas secundariamente, teria se preocupado com a corografia (TAGLIAFERRO, 1952).

Em decorrência do que foi antes exposto pode-se seguramente afirmar que o mundo antigo deixou para a Geografia o impulso teórico ou geral (physis) e o impulso corográfico ou regional, além, claro, do impulso naturalista e da conformação enciclopédica (BARROS, 2004). A cisão mencionada se propagou para o Islã, como resultado das traduções de trabalhos científicos gregos promovidas pelos califas esclarecidos, como Al Mamum, Abu Takub, e outros (IBN KALDUN, 1958, p.147, v.III; AUFRET, 2005, p.11), produzindo-se corógrafos como Ibn Batuta e Ibn Kaldum (BARROS, 2005).

\section{A FACE MODERNA DO PENSAMENTO COROGRÁFICO OU REGIONAL}

Historiadores da disciplina reconhecem a obra Geographia Generalis (1664) de Bernardo Varenius, editada originalmente em 1650 em Amsterdã, como o trabalho transição entre as heranças do Renascimento e os desafios e ousadias do Iluminismo, ou Época da Razão ou do Esclarecimento, como se costuma dizer. Nesta obra Varenius refletiu pioneiramente sobre o alcance, a posição e a função da Geografia Regional, à qual chamava de geografia especial, em oposição à geografia geral. Ele propôs uma harmonia funcional para a tradicional cisão entre o padrão metodológico descritivo (corográfico) e o padrão generalizador (physis) dentro da Geografia.

Os trabalhos geográficos nos séculos 16 e 17 oscilavam entre os dois padrões e, tal qual na obra de Peter Apian (Astronomicum caesareum e Cosmographicus líber, 1524), há consciência da coexistência das duas grandes atitudes metodológicas. Acosta (História Natural y Moral de Las Índias, 1590), por exemplo, oferece corografia e ousa produzir generalizações, conforme apreciação de Humboldt (1952, vol.1, p.48). Acosta teria se antecipado mesmo a Humboldt quando explorou o tema do controle da temperatura pela altitude (BUTZER, 1992, p.557), e generalizou relações entre os geofatores (relevo, clima, planta).

A obra de Bernardo Varenius - a Geographia Generalis (1664) - é reputada como responsável por um passo decisivo na História do pensamento geográfico. A razão para isto é que Varenius não apenas reconheceu a divisão entre a physis e a corografia, mas também, em reconhecendo tal cisão, refletiu sobre a mesma diante dos desenvolvimentos da astronomia e das crescentes necessidades de registrar as características das novas terras trazidas à observação e ao domínio da expansão imperial europeia. Observe-se que, à época, o mundo dos Países Baixos - onde Varenius vivia - havia se tornado o grande centro europeu para os physikóis, especialmente Leiden para os astrônomos. As reflexões de Varenius levaram-no a propor uma harmonização funcional dos dois padrões metodológicos dentro da Geografia, como solução para o problema da dissociação que parecia se aprofundar.

Além das informações cartográficas regionais produzidas nas oficinas do core imperial - combinando num mesmo espaço de representação a pintura realista da Escola da Paisagem (obras de Franz Post) e a informação propriamente cartográfica, combinação esta identificada por Besse (2006, p.25) como marca do período -, observe-se o 
exemplo do conhecido "Relatório de Elias Herckmans", de fato uma monografia. Cultivado nas humanidades, por então governador da Paraíba, Herckmans foi trazido por Nassau a Pernambuco junto com outros artistas, cientistas e intelectuais. O trabalho é uma geographica especialis, na terminologia de B. Varenius, e exemplifica o modelo do estudo geográfico regional produzido no mundo esclarecido dos Países Baixos, à época em que Varenius discutia a estrutura ou a arquitetura geral da Geografia (HERCKMANS, 1982): estudo realista, naturalista, factual ou positivo e prático.

\section{A INSTITUCIONALIZAÇÃO DA GEOGRAFIA E A FORMATAÇÃO DA GEOGRAFIA REGIONAL}

Carl Ritter (1779-1859), ao contrário de Humboldt - este advogado do método do positivo das comparações e generalizações -, se preocupou em discutir as técnicas da divisão do espaço geográfico em regiões (critérios e técnicas da regionalização); por exemplo, perguntando-se quais seriam os melhores critérios ou marcos para proceder às delimitações regionais na Europa, se os critérios naturais ou os humanos (CAPEL, 1981, p.42; TATHAM, 1967, p.49).

Reflexões assim posicionaram Carl Ritter entre os pensadores regionais dentro da discussão doutrinária na Geografia. Apesar disto, contudo - o que revela que o regional e o geral constituem partes congênitas do horizonte do pensamento geográfico, Ritter ousou também doutrinar physis no sentido de propagar o método comparativo, como se vê na sua obra Introdução à Geografia Geral Comparada (RITTER, 1974, p.114115; NICOLAS-OBADIA, 1974, p.14). E, para reforçar mais ainda a ideia de que o regional e o geral andam sempre ao mesmo tempo separados e juntos nos momentos ontológicos da Geografia, Humbold, o grande fixador e doutrinador do método positivo, deixou escritos corográficos sobre o México.

No caso de Ratzel (1844-1904), pioneiro da institucionalização, a região seria um meio geográfico, conceito drenado da biologia aonde havia se dado a sua formação universitária. A região possuiria para ele uma conformação orgânica, e as espécies nas suas migrações, incluindo a humana, precisariam se adaptar às regiões. Vivia-se, à época, a transição demográfica europeia - como o mostra a repercussão do estudo de Ravenstein (1980), As Leis da Migração, em 1885 -, com massas de população deixando o Velho Continente em direção à América. A grande questão quanto à superfície do planeta, quanto ao espaço geográfico, é: como se realiza, como é possível a adaptação das populações humanas aos novos meios ou ambientes regionais (SAUER, 1971, p.250). A América, de norte a sul, se tornara uma espécie de laboratório que testava a capacidade de adaptação humana aos novos meios geográficos (RATZEL, 1988).

O europeu, com a sua cultura, teria de se haver diante dos novos meios geográficos aos quais deveria se adaptar, não desejasse por eles ser tragado e jogado para os "estágios atrasados" (!!!) da história humana. As populações estavam condenadas a adaptar os seus assentamentos ao espaço geográfico (BARROS, 2012b).

Região, meio, adaptação das populações, cultura/tecnologia e chances de progresso - sobre esta última ideia, ver Bury (1932), Barrows (1923), Brunhes (1962), La Blache (1954, 2012), e outros - são termos indissociáveis na Geografia Regional do final do século XIX e primeira metade do século 20. Esta Geografia Regional, vista como Ecologia Humana (BARROS, 2016), apoia-se interdisciplinarmente nos estudos históricos, antropológicos e nas disciplinas naturais (STODDART, 1966; CLAVAL, 1974; SAUER, 1971, p.245; SPETH, 1999), exibindo um caráter integrador, harmonizador e enciclopédico. O conceito chave é a região geográfica.

Ratzel, otimistamente, doutrinava que o meio - os quadros regionais, a região teria, sim, a sua dose de influência sobre as possibilidades de progresso para os que nele habitavam, na medida em que os elementos deste meio (geofatores: rios, oceanos, montanhas, florestas, etc) favoreciam ou dificultavam o espalhamento das invenções adaptativas ao meio. Adaptar-se ao espaço geográfico seria superar - com os 
mecanismos ou as ferramentas adaptativas, tal qual o telégrafo, ou a irrigação, ou as correções nos solos, ou as obras de drenagens, ou a abertura das estradas de ferro, ou a imprensa, etc - o isolamento regional que estancava o progresso ou o "avanço" histórico, digamos assim. O isolamento bloquearia a mudança cultural rumo à interação com os mercados, e à integração às circunstâncias da urbanização e da industrialização expansivas nos quadros dos imperialismos.

Não obstante a sua inserção no coração das discussões regionais anteriormente mencionadas, acontecidas ao final do século XIX e primeiras décadas do século XX, reconhece-se que o paradigma difusionista projetou-se tanto para a Geografia Teórica (neopositivista) quanto a para a Geografia Historicista-Econômica que se propagaram com o crescimento das burocracias - as "usinas de produzir Geografia", nas palavras de M. Santos, 2002 - nos anos da Guerra Fria. Deste modo, o difusionismo modernizador que abria a região às mudanças, ao progresso - foi tomado como missão pelas burocracias que promoveram sistemáticos estudos das redes, das centralidades e dos polos de desenvolvimento, em suma, burocracias que manejaram ferramentas dissolventes da tradição, do caráter e do isolamento regionais. Estes estudos foram aplicados principalmente às chamadas paisagens periféricas, abrindo espaços institucionais de reprodução às classes médias de diferentes colorações ideológicas (BERDOULAY, 2012, p.109).

O fato é que a Geografia Regional - cujo grande divulgador no Brasil foi Carlos Miguel Delgado de Carvalho (1884-1980) (BARROS, 2008; KOHLHEPP, 2015) -, sofreu críticas muito severas a partir dos anos de 1950, críticas expressas em trabalhos como o de Kimble (1951) observando os limites e o eurocentrismo do seu escopo, quer críticas representadas pelo apelo positivista hiperdoutrinário de Schaeffer (1977) que não reconhecia nenhum valor científico no pensamento regional. Aquela Geografia humana ou cultural regional, a Geografia Regional propriamente dita com a marca pessoal do scholar, sofreria as críticas e a competição do padrão disciplinar tópico ou sistemático característico das equipes modernizadoras militantes do planejamento do progresso (BARROS, 2008).

\section{CONSIDERAÇÕES FINAIS}

Críticos afirmaram, e isto ficou antes exposto, que a região geográfica, tal como foi imaginada até meados do século $X X$, assemelhava-se a uma espécie de entidade metafísica, a algo ao mesmo tempo racional - quer dizer, passível de decomposição analítica dos seus fatores - e indefinível. A dimensão regional assim concebida traria em si uma espécie de "destino" - ou "vocação" da área geográfica. Neste nível conceptual coletivo, ou nível regional geográfico integrado, o individual se submeteria à suposta harmonia das combinações entre os fatores físicos, biológicos e humanos, formando a totalidade regional (idiográfica) equilibrada, obscurecendo-se conflitos e diferenciações efetivamente existentes no âmbito regional (DUNCAN, 1980, 189-191).

Contudo, não obstante todo o criticismo manifestado pelo pensamento de caráter positivista e doutrinário em relação ao pensamento regional, e apesar das intensas controvérsias que cercaram e continuam a cercar - ainda que de modo mais moderado - os debates entre os estilos metodológicos dentro da História da disciplina, havemos de reconhecer que o pensamento regional e o pensamento tópico ou sistemático, cada qual com a sua funcionalidade, ambos estão interligados e compõem a estrutura mesma da Geografia, e esta dualidade é sempre reatualizada diante de novos contextos e desafios históricos. 


\section{REFERÊNCIAS}

AGNEW, J.; LiVINGSTONE, D.; ROGERS, A. (Ed.). Human Geography: an essential anthology. London: Blackwell, 1996.

AUFRET, S. Apresentação. In: IBN TUFAYL, obra citada, 2005.

BARNES, $\mathrm{H}$. The relation of Geography to the writing and interpretation of history. The Journal of Geography, v. XX, n. 9, p. 35-40, 1921.

BARROS, N. Notas sobre contribuições da antiguidade clássica ao pensamento geográfico. Revista de Geografia, Recife, Universidade Federal de Pernambuco, v. 21, n. 2, p. 7784, 2004.

BARROS, N. Ibn Kaldun, a dinámica dos assentamentos humanos e as funções urbanas no Islã histórico. Mercator, Fortaleza, v. 4, n.8, p. 7-14, 2005.

BARROS, N. Delgado de Carvalho e a Geografia no Brasil como arte da Educação Liberal. Estudos Avançados, IEA/USP, São Paulo, n.62, p.317-334, 2008.

BARROS, N. Por que as destinações turísticas no Nordeste do Brasil não declinam? -uma interpretação geográfica. Recife: Editora da Universidade Federal de Pernambuco, 2009. BARROS, N. O geral e o regional na História da Geografia. Revista Geográfica, IPGH/ OEA, México, n.152, p.9-30, 2012a.

BARROS, N. Antropogeografia: ecologia, cultura e europeização. Revista de Geografia, Recife, Universidade Federal de Pernambuco, v.29, n.2, p. 25-33, 2012b.

BARROS, N. A modernização da Geografia como Ecologia Humana. In: ALMEIDA, M.; AZEVEDO, S. (Org.). Diálogos socioambientais e perspectivas culturais. P. Afonso: Editora da Sociedade Brasileira de Ecologia Humana, 2016, p.18-37.

BARROWS, H. Geography as Human Ecology. Annals of The Association of American Geographers, v. 13, n. 1 , p. 1-14, 1923.

BERDOULAY, V. Espaço e cultura. In: CASTRO, I. et al (Org.). Olhares geográficos. Rio de Janeiro: Bertrand, 2012, p.101-131.

BESSE, J-M. Ver a Terra: seis ensaios sobre a paisagem e a geografia. São Paulo: Perspectiva, 2006.

BORNHEIM, G. (Org.). Os Filósofos pré Socráticos: coletânea. São Paulo: Cultrix, 1967. BRUNHES, J. Geografia humana. Rio de Janeiro: Fundo de Cultura Econômica, 1962.

BURY, J. The ideia of progress. New York: MacMillan/Dover, 1932.

BUTZER, K.. From Columbus to Acosta: Science, Geography and the New World. Annals of The Association of American Geographers, v.82, n.3, p.543-565, 1992.

CAPEL, H. Filosofía y ciencia en la Geografía contemporánea: una introducción a la Geografía. Barcelona: Barcanova, 1981.

CARACI, I. Modern Geography in Italy: From the Archives to Environmental Management. In: DUNBAR, G. (Ed.). Geography: discipline, profession and subject since 1870 - an international survey. The Netherlands: Kluver Academic Publishers, 2001. 2001, p.121151.

CLAVAL, P. Evolución de la Geografía Humana. Barcelona: Oikus-tau, 1974.

DUNBAR, G. (Ed.). Geography: discipline, profession and subject since 1870 - an international survey. The Netherlands: Kluver Academic Publishers, 2001.

DUNCAN, J. The Superorganic in the American Cultural Geography. Annals of The Association of American Geographers, v. 70, n. 2, p. 181-198, 1980.

GLAECKEN, C. Traces on the Rhodian Shore. Los Angeles: University of California Press, 1967.

GOMES, P. (1995) O conceito de região e sua discussão. In: CASTRO, I. ; CORREIA, R.; GOMES, P. (Org.). Geografia: conceitos e temas. Rio de Janeiro: Bertrand, pp.49-76. 
HERCKMANS, E. Descrição geral da Capitania da Paraíba. João Pessoa: Gráfica Editora União, 1982.

HOLT-JENSEN, A. Geography: history and concepts. London: P. Chapman, 1988.

HUMBOLDT, A. Cosmos: a sketch of a Physical description of the Universe. London: Henry G. Bohn, 1952, 4v.

IBN TUFAYL, MUHAMMAD IBN 'ABD AL-MALIK (1105-1186). O filósofo autodidata. São Paulo: Editora Unesp, 2005.

IBN KALDUN (1332-1406). The Muqaddimah: an introduction to history. London: Routledge \& Kegan Paul, 1958, 3 v.

KIMBLE, G. The inadequacy of the regional concept. In: AGNEW et al, Human Geography..., AGNEW, J.; LIVINGSTONE, D.; ROGERS, A. (Ed.). Human Geography: an essential anthology. London: Blackwell, 1996. 1996, p. 492-512. (Orig. publicado em 1951).

KOHLHEPP, G. Pioneiros brasileiros nas pesquisas geográficas de desenvolvimento regional: Orlando Valverde e Hilgard O'Reilly Sternberg. Revista Brasileira de Desenvolvimento Regional, v.3, n.1, p.27-54, 2015.

LA BLACHE, P. Significado e objeto da Geografia Humana. In: LA BLACHE, P. Princípios de Geografia Humana. Lisboa: Cosmos, p.27-45, 1954.

LA BLACHE, P. O princípio da geografia geral. In: HAESBAERT, R.; RIBEIRO, G. (Ed.). Vidal, Vidais: textos de geografia humana, regional e política. Rio de Janeiro: Bertrand, 2012, pp.47-66.

LENCIONI, S. Região e geografia. São Paulo: Edusp, 2003.

MCKEON, R. (Ed.). The basic works of Aristotle. New York: The Modern Library,

NICOLAS-OBADIA, G. Introdução. In: RITTER, C. Introducción à la Géographie Generale Comparée. Cahiers de Géographie de Besançon, n. spéciale 22, 1974. (Orig. publ. em 1852). 1974, 5-32.

PATTISON, W. The four traditions of Geography. The Journal of Geography, v.63, n.5, p. 211-216, 1964.

PTOLEMY, C. The Almagest: I-V. In: HUTCHINS, R. (Ed.). Great Books of The Western World. Chicago: E. Britannica, 1952, v. 16, p.1-480.

RATZEL, F. Sketches of Urban and Cultural Life in North America. New Brunswick: Rutgers University Press, 1988. (Orig. publ. em 1876)

RAVENSTEIN, E. As leis da migração. In: MOURA, H. (Org.). Migrações Internas: textos selecionados. Fortaleza: Banco do Nordeste do Brasil, 1980, v. 1, p.23-88. (Orig. publicado em 1885).

RITTER, C. Introducción à la Géographie Generale Comparée. Cahiers de Géographie de Besançon, n. spéciale 22, 1974. (Orig. publ. em 1852).

SANTOS, M. (2002). Entrevista ao Dr. J. Borzachielo da Silva. Mercator, Fortaleza, U. Federal do Ceará, v.1, n.1.

SAUER, C. The formative years of Ratzel in the United States. Annals of The Association of American Geographers, v. 61, n.2, p. 245-254, 1971.

SCHAEFFER, F. Excepcionalismo na Geografia. Boletim de Geografia Teorética, Rio Claro, AGETEO, v.7, n.13, p.5-37,1977. (Pub. original Annals of The AAG, 1953)

SPETH, W. How it came to be: Carl Sauer, Franz Boas and the Meanings of Anthropogeography. Washington: Ephemera Press, 1999.

STODDART, D. Darwin's impact on Geography.Annals of The Association of American Geographers, v. 56, p.683-689, 1966.

STRABO. The Geography of Strabo. London: Heinemann, 1949, cit. por UNWIN, ob.cit, 1992. 
TAGLIAfERRO, R., Introd. and Notes. In: PTOLEMY, C. ob. cit, 1952, p.x e 1-3.

TATHAM, G. Geography in the Nineteenth Century. In: TAYLOR, G. (Ed.). Geography in the Twentieth Century: a study of growth, fields, techniques, aims and trends. London: Methuen, 1967. 1967, p.28-69, chapter II.

TAYLOR, G. (Ed.). Geography in the Twentieth Century: a study of growth, fields, techniques, aims and trends. London: Methuen, 1967.

UNWIN, T. The place of Geography, N.York: Longman, 1992.

VARENIUS, B. Geographia generalis. Amstelodami: Officina Elzeviriana, 1664.

NILSON CORTEZ CROCIA DE BARROS

(Professor Titular Departamento de Geografia - Universidade Federal de Pernambuco Endereço para correspondência: Avenida Prof. José dos Anjos, 110, apt.801 - Bairro de Casa Amarela - 52051-345 Recife, Estado de Pernambuco.

E mail: nccrocia@ufpe.br)

\title{
A ABORDAGEM CONTEXTUAL DE VINCENT BERDOULAY: DESMISTIFICANDO A HISTÓRIA DO PENSAMENTO GEOGRÁFICO
}

\author{
GEOGRAFIA, Rio Claro, v. 43, n. 2, p. 357-360, mai./ago. 2018.
}

BERDOULAY, Vincent. A escola francesa de Geografia: uma abordagem contextual. Trad. Oswaldo Bueno Amorim Filho. 1. Ed. São Paulo: Perspectiva, 2017. ISBN: 9788527311052

A obra "A escola francesa de Geografia: uma abordagem contextual" apresenta uma análise aprofundada do movimento de gênese e consolidação da escola francesa de Geografia no período compreendido entre os anos de 1870 a 1914, o que faz dela uma referência fulcral para os estudos sobre a epistemologia e a história do pensamento geográfico. Publicada na França no ano de 1981, ela é resultado da tese de doutorado "Societal context and the emergence of the French school of geography (1870-1914)", defendida no ano de 1974 pelo geógrafo francês Vincent Berdoulay, sob a orientação de David J.M. Hooson, no importante centro para geografia cultural e histórica: Universidade da Califórnia (Berkeley), nos Estados Unidos. O reconhecimento da relevância desta pesquisa, bem como sua continuidade e atualização levaram à publicação de outras duas edições da obra, nos anos de 1995 e 2008. Esta última foi traduzida para o português pelo geógrafo Oswaldo Bueno Amorim Filho (PUC-Minas), culminando na publicação da edição brasileira no ano de 2017, prefaciada por Eduardo Marandola Jr. (Unicamp).

Para a consecução do seu objetivo, examinar a trajetória da geografia (francesa), Berdoulay propõe uma abordagem metodológica inovadora, por ele denominada de contextual, ao qual convida-nos a uma leitura interseccional sobre os fatores internos e externos que esteiam o devir do pensamento científico. Neste sentido, a obra de Berdoulay pode subsidiar o desenvolvimento de outros estudos sobre a história e a sociologia das ciências. O autor considera as descontinuidades das tendências científicas, a interdependência das ciências e as condições para a realização das pesquisas, tanto internas à própria ciência quanto as de âmbito mais macro, como as relações políticoeconômicas da sociedade sem, contudo, concebe-las como determinantes para totalidade do fazer científico. Este olhar lhe permitiu articular elementos históricos, epistemológicos, conceituais, econômicos e sociopolíticos, como também fundamentou o repúdio à linearidade da interpretação finalista que acaba por atribuir superioridade intelectual a determinadas perspectivas científicas, principalmente aquelas que conseguiram posteridade no âmbito acadêmico-social. 